\title{
Prevalence of cardiometabolic risk factors and metabolic syndrome in obese Kuwaiti adolescents
}

This article was published in the following Dove Press journal:

Diabetes, Metabolic Syndrome and Obesity: Targets and Therapy

24 October 2014

Number of times this article has been viewed

\section{Shurooq A Boodai' \\ Lynne M Cherry ${ }^{2}$ \\ Naveed A Sattar ${ }^{2}$ \\ John J Reilly ${ }^{3}$}

'University of Glasgow School of Medicine, Yorkhill Hospitals, Glasgow, Scotland; ${ }^{2}$ Institute of Cardiovascular and Medical Sciences, British Heart Foundation Glasgow Cardiovascular Research Centre, University of Glasgow, Glasgow, Scotland; ${ }^{3}$ University of Strathclyde Physical Activity for Health Group, School of Psychological Sciences and Health, Glasgow, Scotland
Correspondence: Shurooq A Boodai University of Glasgow School of Medicine, Yorkhill Hospitals, Glasgow, G3 8SJ Scotland Email s.boodai.I@research.gla.ac.uk
Background: Childhood and adolescent obesity is associated with insulin resistance, abnormal glucose metabolism, hypertension, dyslipidemia, inflammation, liver disease, and compromised vascular function. The purpose of this pilot study was to determine the prevalence of cardiometabolic risk factor abnormalities and metabolic syndrome (MetS) in a sample of obese Kuwaiti adolescents, as prevalence data might be helpful in improving engagement with obesity treatment in future.

Methods: Eighty obese Kuwaiti adolescents (40 males) with a mean (standard deviation) age of 12.3 years ( 1.1 years) participated in the present study. All participants had a detailed clinical examination and anthropometry, blood pressure taken, and assessment of fasting levels of C-reactive protein, intracellular adhesion molecule, interleukin-6, fasting blood glucose, insulin, liver function tests (alanine aminotransferase, aspartate aminotransferase, gamma glutamyltransferase), lipid profile (cholesterol, low-density lipoprotein cholesterol, high-density lipoprotein cholesterol, triglycerides), insulin resistance by homeostasis model assessment, and adiponectin. MetS was assessed using two recognized criteria modified for use in younger individuals.

Results: The cardiometabolic risk factors with highest prevalence of abnormal values included aspartate aminotransferase ( $88.7 \%$ of the sample) and insulin resistance by homeostasis model assessment (67.5\%), intracellular adhesion molecule (66.5\%), fasting insulin (43.5\%), C-reactive protein $(42.5 \%)$, low-density lipoprotein cholesterol (35.0\%), total cholesterol $(33.5 \%)$, and systolic blood pressure (30.0\%). Of all participants, 96.3\% (77/80) had at least one impaired cardiometabolic risk factor as well as obesity. Prevalence of MetS was $21.3 \%$ according to the International Diabetes Federation definition and 30\% using the Third Adult Treatment Panel definition.

Conclusion: The present study suggests that obese Kuwaiti adolescents have multiple cardiometabolic risk factor abnormalities. Future studies are needed to test the benefits of intervention in this high-risk group. They also suggest that prevention of obesity in children and adults should be a major public health goal in Kuwait.

Keywords: obesity, adolescents, prevalence, cardiometabolic risk factors, metabolic syndrome

\section{Background}

Childhood and adolescent obesity is associated with insulin resistance, abnormal glucose metabolism, hypertension, dyslipidemia, inflammation, liver disease, and compromised vascular function. ${ }^{1-5}$ As with obesity, these impairments could track into young adulthood, which increases the risk of cardiometabolic diseases and even certain types of cancer independent of adult weight. ${ }^{6,7}$ 
The detrimental effects of adolescent obesity on subsequent risk of cardiovascular disease are partly mediated by the presence of cardiometabolic risk factors. ${ }^{8}$ Cardiovascular disease is the leading cause of morbidity and mortality worldwide with an estimate of 17.3 million deaths in 2008 , and by 2030 this number could reach up to 23.3 million. ${ }^{9}$ It is widely believed that atherosclerosis begins in childhood and progresses into adulthood. ${ }^{10,11}$ As the number of cardiovascular disease risk factors increases in childhood, so does the severity of both coronary and aortic atherosclerosis in young adulthood. ${ }^{3}$ In the Netherlands, two-thirds of obese children and adolescents had more than one cardiovascular disease risk factor in one study. ${ }^{12}$ In Germany and Switzerland, around $50 \%$ of obese children had at least one cardiometabolic risk factor in one study. ${ }^{13}$

The presence of obesity in childhood and adolescence is also related to the development of fatty liver or steatosis, which is the most common liver abnormality in this age group. ${ }^{14}$ Steatosis can be present with or without elevated liver enzymes (aminotransferases). ${ }^{15}$ For the long term, the ramifications of having persistently elevated liver enzymes and steatosis are important and could lead eventually to the development of cirrhosis. ${ }^{14,16}$

In two previous studies of obese adolescents in Kuwait, we observed that their health-related quality of life was unimpaired compared with nonobese peers, ${ }^{17}$ and that their engagement with therapy to treat obesity was poor. ${ }^{18}$ It is possible that knowledge of the presence of cardiometabolic risk factors in obese adolescents may increase the engagement of adolescents and their families with efforts to treat obesity. The aim of the present study was therefore to estimate the prevalence of cardiometabolic risk factors in obese adolescents in order to provide evidence that might be useful to future obesity treatment. In the present study, we carried out assessments of obesity-related cardiometabolic risk factors that could impair vascular health and liver function. These included lipid profile (cholesterol, low-density lipoprotein [LDL], very low-density lipoprotein, high-density lipoprotein [HDL], triglycerides [TG]), interleukin-6 (IL-6), intracellular adhesion molecule (ICAM), C-reactive protein (CRP), adiponectin, liver function tests (alanine aminotransferase [ALT], aspartate aminotransferase [AST], gamma glutamyltransferase [GGT]), and insulin resistance by homeostasis model assessment (HOMA-IR).

\section{Materials and methods}

\section{Participants}

The study was the baseline element of an intervention to treat adolescent obesity using a randomized controlled trial, the National Adolescent Treatment Trial for Obesity (NATTO). ${ }^{18}$ We recruited 80 obese adolescents participating in the NATTO in Kuwait City ${ }^{18}$ at the preintervention stage of the trial. They were all at or above the age- and sex-adjusted 95th body mass index (BMI) percentile, which defines obesity. ${ }^{19}$ Age ranged from 10 years to 14 years. All participants underwent physical examination including anthropometric assessment (weight, height, BMI, waist circumference) and had no medical or surgical history. All participants and their parents consented to take part in the study. The study was approved by the Medical Research Committee of the Ministry of Health - Kuwait.

Blood samples were drawn for analysis for fasting blood glucose (FBG), fasting insulin, cholesterol, LDL, HDL, TG, ALT, AST, GGT, CRP, IL-6, ICAM, and adiponectin. Insulin resistance was measured by HOMA-IR (fasting insulin $\times$ fasting glucose/22.5). ${ }^{20}$

Blood pressure was measured when the participant was sitting quietly in the upright position, with the correct cuff size applied to the right arm. The reading was repeated three times, and the average of the three readings was taken.

\section{Biochemical assessment}

Cholesterol, TG, HDL, sensitive CRP, ALT, AST, and GGT assays were assessed using a C311 Roche analyzer; sensitive CRP immunotubidimetric assays with cholesterol, TG, HDL, ALT, AST, and GGT being enzymatic colorimetic. Kits were supplied by Roche Diagnosticx GmbH. IL-6, ICAM, adiponectin, and insulin analysis (enzyme-linked immunosorbent assays) was assessed using kits supplied by R\&D Systems Europe Ltd (Oxford, UK) and Mercodia AB.

\section{Cutoff points for defining the cardio- metabolic risk factors and metabolic syndrome}

There are two commonly used cutoff points for FBG $(\mathrm{mmol} / \mathrm{L})$, the World Health Organization (WHO) normal cutoff $<6.1 \mathrm{mmol} / \mathrm{L}^{21}$ and the American Diabetes Association normal cutoff $<5.6 \mathrm{mmol} / \mathrm{L} .{ }^{22}$ However, in Kuwait, the official criterion used for diagnosing and classifying diabetes mellitus is the WHO criterion, ${ }^{23}$ and so that was used in the present study.

Ideally, hyperinsulinemia is defined if insulin level exceeds the normal value according to the pubertal stage, due to the impact of physiological insulin resistance of puberty. ${ }^{24}$ However, Tanner staging was not assessed during the clinical examination in the present study for social and cultural reasons. Thus, standard values of normal, borderline, and 
high fasting insulin levels proposed by the American Heart Association scientific statement were chosen. ${ }^{25}$

HOMA-IR is a proxy for insulin resistance and is widely used in clinical settings and research, with high reliability in determining insulin resistance..$^{20}$ There is still a debate about the appropriate cutoff point for HOMA-IR, with proposed values of $\geq 2.5,{ }^{26,27} \geq 1.77,{ }^{28}$ and $>3.16 .{ }^{20}$ Keskin et $\mathrm{al}^{20}$ found that HOMA-IR was the most sensitive and most specific of three proxies for defining insulin resistance, and the cutoff point for insulin resistance diagnosis based on HOMA-IR was $3.16,{ }^{20}$ so that definition was used in the present study.

Assessment of lipid profile for the participants included fasting TG, fasting cholesterol, fasting LDL, and fasting HDL. Jolliffe and Janssen ${ }^{29}$ developed age- and sex-specific percentiles for lipoproteins and cholesterol, starting from age 12 years to age 20 years. However, our participants were aged 10-14 years, and it was not possible to use these lipoprotein percentiles for the whole sample. Therefore, the reference values for these parameters were taken from the National Cholesterol Education Program, with fixed cutoff points for normal, borderline, and high values regardless of sex and age. ${ }^{30}$

Liver function tests were obtained in all participants and included ALT, AST, and GGT. The upper limit for ALT and AST in adults differs between populations, and differences exist between males and females. ${ }^{31}$ However, in studies examining the prevalence of abnormal ALT, AST, and GGT in adolescents, the most commonly used cutoff points were $>40 \mathrm{U} / \mathrm{L},>40 \mathrm{U} / \mathrm{L}$, and $>35 \mathrm{U} / \mathrm{L}$, respectively. ${ }^{15,32,33}$ Therefore, these were the values that we used as cutoff points in our study.

Markers of inflammation were assessed in all participants, including CRP. ${ }^{34}$ Generally, normal and abnormal levels of CRP were developed for the adult population, ${ }^{34,35}$ and some studies found that the normal range in healthy adults was from $0.08 \mathrm{mg} / \mathrm{L}$ to $6.1 \mathrm{mg} / \mathrm{L} .{ }^{36}$ Our study used the cutoff points set by the American Heart Association and the Centers for Disease Control and Prevention. ${ }^{34}$

The inflammatory cytokine IL-6 has an age-related variability with peak physiological elevation around age 4 years and 15 years in relation to cartilage and bone development. ${ }^{37}$ In the literature, precise reference ranges for IL-6 vary greatly depending on the age, weight status, and sex of the participants tested. ${ }^{37-39}$ In the present study, we used the reference range of the control group (healthy controls $n=37$ ) from a study by Makni et $\mathrm{al}^{40}(>3.9 \mathrm{pg} / \mathrm{mL})$.

Inflammatory plasma soluble adhesion molecules (ICAM) were also measured in all of the participants. ${ }^{41}$ The literature shows that ICAM values are age related, and when applying the cutoff point for our study we chose a study by Andrys et $\mathrm{al}^{42}$ to establish reference range for serum soluble adhesion molecules in healthy children and adolescents aged 6-15 years, defined by values between the fifth and 95th percentiles for each inflammatory marker. The normal cutoff range for those aged 6-10 years was $206.8-486.8 \mathrm{ng} / \mathrm{mL}$, and for those aged $11-15$ years was $184.1-355.0 \mathrm{ng} / \mathrm{mL}{ }^{42}$

The anti-inflammatory adipokine adiponectin was measured in all participants in the fasting state. It is normally present in plasma concentrations of $2-20 \mu \mathrm{g} / \mathrm{mL} .{ }^{43}$ Most studies comparing adiponectin concentration in obese adolescents with its concentration in healthy controls referred to "low levels" when adiponectin concentration was $<5 \mu \mathrm{g} / \mathrm{mL}$, as compared with its concentration in healthy control subjects at $>10 \mu \mathrm{g} / \mathrm{mL}^{44-46}$ Therefore, in the present study, we used the same cutoff points.

Hypertension was defined as a systolic and or diastolic blood pressure $\geq 95$ th percentile for age, sex, and height, measured on three separate occasions. ${ }^{47}$ Metabolic syndrome (MetS) was defined according to the International Diabetes Federation (IDF) definition ${ }^{48}$ and the Third Adult Treatment Panel (ATP III) definition. ${ }^{49}$ Participants were classified as having MetS if they had a waist circumference $\geq 90$ th percentile plus two or more of the following criteria according to the IDF definition: $\mathrm{TG} \geq 1.7 \mathrm{mmol} / \mathrm{L}, \mathrm{HDL}<1.03 \mathrm{mmol} / \mathrm{L}$, blood pressure $\geq 130 / 85 \mathrm{mmHg}$, and $\mathrm{FBG} \geq 5.6 \mathrm{mmol} / \mathrm{L}$. Classification of MetS according to the ATP III definition was based on the presence of three or more of the following criteria: waist circumference $\geq 90$ th percentile, $\mathrm{TG} \geq 1.24 \mathrm{mmol} / \mathrm{L}$, $\mathrm{HDL} \leq 1.03 \mathrm{mmol} / \mathrm{L}$, blood pressure $\geq 90$ th percentile, and $\mathrm{FBG} \geq 6.1 \mathrm{mmol} / \mathrm{L}$.

\section{Results \\ Characteristics of study participants}

Table 1 shows the mean and standard deviation (SD) of all measured parameters for the participants $(n=80)$. The mean age was 12.3 years (SD 1.1 years).

\section{Prevalence of cardiometabolic risk factors}

Twenty-six out of the 80 participants (32.5\%) had systolic and/or diastolic blood pressure $\geq 95$ th percentile for age, sex, and height. Hyperglycemia and hyperinsulinemia were present in $2.5 \%$ (two of 80 ) and $43.8 \%$ (35/80) of participants, respectively. Insulin resistance as defined by HOMA-IR value $>3.16^{20}$ was found in $67.5 \%$ (54/80) of participants. Out of the 80 participants, $27.5 \%(22 / 80)$ had a high TG level, $33.8 \%$ $(27 / 80)$ had a high total cholesterol level, 20\% (16/80) had a 
Table I Descriptive parameters of the adolescents according to sex, mean (standard deviation)

\begin{tabular}{|c|c|c|c|c|c|}
\hline \multirow[t]{2}{*}{ Variables } & \multirow[t]{2}{*}{$\begin{array}{l}\text { All participants } \\
(\mathrm{n}=\mathbf{8 0})\end{array}$} & \multirow[t]{2}{*}{$\begin{array}{l}\text { Boys } \\
(n=40)\end{array}$} & \multirow[t]{2}{*}{$\begin{array}{l}\text { Girls } \\
(n=40)\end{array}$} & \multicolumn{2}{|c|}{$\begin{array}{l}\text { Number of participants } \\
\text { with abnormality (\%) }\end{array}$} \\
\hline & & & & Borderline & High \\
\hline Age, years & $12.3(1.1)$ & $12.4(1.2)$ & $12.3(1.1)$ & na & na \\
\hline BMI Z-score & $2.2(0.3)$ & $2.2(0.3)$ & $2.2(0.3)$ & na & na \\
\hline Waist circumference, $\mathrm{cm}$ & $93.3(12.2)$ & $96.6(12.4)$ & $90.0(11.2)$ & & \\
\hline Systolic blood pressure, $\mathrm{mmHg}$ & $122(\mathrm{II})$ & $125(\mathrm{II})$ & $119(9)$ & na & $24(30.0 \%)$ \\
\hline Diastolic blood pressure, $\mathrm{mmHg}$ & $77(8)$ & $78(8)$ & $77(7)$ & na & $14(17.5)$ \\
\hline Total cholesterol, $\mathrm{mmol} / \mathrm{L}$ & $4.7(0.9)$ & $4.7(1.0)$ & $4.7(0.8)$ & $25(31.5 \%)$ & $27(33.8 \%)$ \\
\hline $\mathrm{LDL}, \mathrm{mmol} / \mathrm{L}$ & $3.0(0.8)$ & $3.0(0.9)$ & $3.0(0.7)$ & $20(25 \%)$ & $28(35.0 \%)$ \\
\hline TG, mmol/L & I.3 (0.5) & $\mathrm{I} .3(0.5)$ & $\mathrm{I} .3(0.5)$ & $26(32.5 \%)$ & $22(27.5 \%)$ \\
\hline $\mathrm{HDL}, \mathrm{mmol} / \mathrm{L}$ & I.I (0.2) & I.I (0.2) & I.I (0.3) & 60 (75\%) low & $16(20.0 \%)$ \\
\hline $\mathrm{FBG}, \mathrm{mmol} / \mathrm{L}$ & $4.7(0.8)$ & $4.8(0.9)$ & $4.5(0.6)$ & na & $2(2.5 \%)$ \\
\hline Fasting insulin, $\mu \mathrm{U} / \mathrm{L}$ & $26.7(23.8)$ & $26.4(25.8)$ & $27.0(22.0)$ & 21 (26.5\%) & $35(43.8 \%)$ \\
\hline HOMA-IR & $6.0(7.3)$ & $6.4(9.2)$ & $5.5(5.0)$ & na & $54(67.5 \%)$ \\
\hline $\mathrm{ALT}, \mathrm{U} / \mathrm{L}$ & $34.2(23.6)$ & $42.2(21.3)$ & $26.1(23.4)$ & na & $21(26.3 \%)$ \\
\hline AST, U/L & $58.1(19.3)$ & $63.3(15.6)$ & $52.8(21.4)$ & na & $71(88.8 \%)$ \\
\hline GGT, U/L & $27.0(12.6)$ & $31.4(13.9)$ & $22.7(9.6)$ & na & $14(17.5 \%)$ \\
\hline CRP, mg/L & $4.2(5.1)$ & $5.0(4.6)$ & $3.5(5.5)$ & 31 (38.5\%) & 34 (42.5\%) \\
\hline IL-6, pg/mL & $2.0(1.8)$ & $1.9(1.5)$ & $2.0(2.1)$ & na & $6(7.5 \%)$ \\
\hline ICAM, ng/mL & $461.3(158.5)$ & $493.2(158.0)$ & $429.4(154.6)$ & na & $53(66.3 \%)$ \\
\hline Adiponectin, ng/mL & $50.7(25.0)$ & $47.0(21.5)$ & $54.4(27.9)$ & na & \\
\hline
\end{tabular}

Abbreviations: ALT, alanine aminotransferase; AST, aspartate aminotransferase; BMI, body mass index; CRP, C-reactive protein; FBG, fasting blood glucose; GGT, gamma glutamyltransferase; HDL, high-density lipoprotein; HOMA-IR, insulin resistance by homeostasis model assessment; ICAM, intracellular adhesion molecule; IL-6, interleukin-6; LDL, low-density lipoprotein; na, not applicable; TG, triglycerides.

low HDL level, and 35\% had a high LDL level. Liver function tests showed high ALT in $26.3 \%$ (21/80) of participants, high AST in $88.8 \%(71 / 80)$ of participants, and high GGT level in $17.5 \%(14 / 80)$ of participants. CRP level was high in $42.5 \%$ (34/80) of participants, IL-6 level was high in $7.5 \%$ (six of 80 ) of participants, ICAM level was high in $66.3 \%$ (53/80) of participants, and adiponectin level was normal in all participants.

Table 2 shows the results of waist circumference, TG, HDL, FBG, systolic blood pressure, and diastolic blood pressure measurements using IDF and ATP III criteria.

Table 2 Metabolic syndrome prevalence using IDF and ATP III criteria in the participants

\begin{tabular}{llll}
\hline $\begin{array}{l}\text { Anthropometric and } \\
\text { biochemical variables }\end{array}$ & $\begin{array}{l}\text { Mean } \\
\text { (standard } \\
\text { deviation) }\end{array}$ & IDF & ATP III \\
\hline Waist circumference $(\mathrm{cm})$ & $93.3(\mathrm{I} 2.2)$ & $66(82.5 \%)$ & $66(82.5 \%)$ \\
TG $(\mathrm{mmol} / \mathrm{L})$ & $1.3(0.5)$ & $12(15 \%)$ & $37(46.5 \%)$ \\
HDL (mmol/L) & $1.1(0.2)$ & $26(32.5)$ & $26(32.5 \%)$ \\
FBG (mmol/L) & $4.7(0.8)$ & $4(5 \%)$ & $2(2.5 \%)$ \\
Systolic blood pressure & $122(\mathrm{II})$ & $9(\mathrm{II} .5 \%)$ & $\mathrm{II}(\mathrm{I} 3.5 \%)$ \\
$\begin{array}{l}\text { Diastolic blood pressure } \\
\text { Metabolic syndrome }\end{array}$ & $77(8)$ & & \\
prevalence & & $17(21.3 \%)$ & $24(30 \%)$ \\
\hline
\end{tabular}

Abbreviations: ATP III, Third Adult Treatment Panel; FBG, fasting blood glucose; HDL, high-density lipoprotein; IDF, International Diabetes Federation; TG, triglycerides.
Seventeen of the 80 participants $(21.3 \%)$ met the diagnosis of MetS by the IDF definition and 24 of the 80 participants $(30 \%)$ met the diagnosis of MetS by the ATP III definition.

\section{Discussion}

The current study is the first to estimate the prevalence of cardiometabolic risk factors and MetS in a group of obese Kuwaiti adolescents. The main finding of this study was the high prevalence of multiple cardiometabolic risk factors. Out of the 16 risk factors measured, eight were high in $\geq 30 \%$ of the participants (Table 1). The cardiometabolic risk factors with the highest prevalence of abnormal values included AST $(88.7 \%$ of the sample), HOMA-IR ( $67.5 \%$ of the sample), ICAM ( $66.5 \%$ of the sample), fasting insulin ( $43.5 \%$ of the sample), CRP ( $42.5 \%$ of the sample), LDL ( $35.0 \%$ of the sample), cholesterol ( $33.5 \%$ of the sample), and systolic blood pressure (30.0\% of the sample); $96.3 \%$ (77/80) of participants had at least one cardiometabolic risk factor as well as obesity.

As mentioned previously, participants of this study were recruited from the baseline stage of a randomized controlled trial of an office-based treatment trial for adolescent obesity in Kuwait (NATTO). One of the findings of the NATTO was poor engagement with treatment, as evidenced by the poor attendance of families in both the intervention and control arms of the trial. ${ }^{18}$ Therefore, findings from the present study might have been useful to demonstrate to the adolescents and 
their families that their obesity was a medical problem, and so possibly persuade them to engage more with treatment. Moreover, all of the measured parameters in the present study, except for adiponectin, are readily accessible by physicians working in the Ministry of Health - Kuwait in the clinical setting, so their measurement could be part of any treatment protocol for adolescent obesity in the future.

Risk factors for cardiovascular disease and type 2 diabetes mellitus have extended their roots to reach children and adolescents. ${ }^{6,7,10,50-54}$ In a study from $\operatorname{Iran}^{55}$ on 5,528 adolescents aged 10-18 years assessing the relationship between multiple cardiometabolic risk factors (total cholesterol, TG, LDL, HDL, blood pressure, and FBG) with BMI, low physical activity, and an unhealthy diet, BMI had the greatest direct effect on total cholesterol, LDL, TG, FBG, and blood pressure and an inverse relationship with HDL, more than that contributed by inactivity and an unhealthy diet. Kelishadi et $\mathrm{al}^{55}$ called for immediate interventions to tackle pediatric obesity and its associated cardiometabolic risk factors in order to prevent future risk of MetS and chronic noncommunicable diseases in Iran.

Kardas et $\mathrm{al}^{56}$ compared the levels of cholesterol, LDL, TG, HDL, FBG, blood pressure, vitamin D, and adiponectin between obese $(n=63)$ and nonobese $(n=51)$ Turkish adolescents aged 10-16 years. Obesity was defined as BMI $>90$ th percentile for an age- and sex-specific Turkish reference population. Cholesterol, LDL, TG, FBG, and blood pressure were significantly higher in the obese group compared with the nonobese group. Adiponectin, vitamin D, and HDL were significantly lower in the obese group compared with the nonobese group. Mean adiponectin value for the obese group was $3.3( \pm 0.89) \mathrm{ng} / \mathrm{mL}$ and in the nonobese group the mean value was $6.0( \pm 1.4) \mathrm{ng} / \mathrm{mL}$.

In the Netherlands, inpatient children and adolescents ( $n=80$, aged between 8 years and 19 years) diagnosed with severe obesity (defined as BMI SDS $\geq 3$ or BMI SDS $\geq 2.3$ with comorbidities according to the growth percentiles of the Fourth Dutch Growth Study) were evaluated for the presence of multiple cardiometabolic risk factors, namely blood pressure, fasting insulin, FBG, HOMA-IR, cholesterol, LDL, TG, HDL, and CRP, ${ }^{57}$ as part of an inpatient treatment trial for their obesity. Data showed that $80 \%$ of the participants had at least one impaired cardiometabolic risk factor as well as severe obesity. In comparison with our study, $90 \%$ of our participants had at least one impairment with regards to the same cardiometabolic risk factors assessed.

In the present study, almost a third of the participants had MetS according to the ATP III definition. ${ }^{58}$ In a study done in Kuwait on apparently healthy female adolescents ( $n=431$, age
10-19 years) to assess the prevalence of MetS using the same definitions that we applied to our study, it was found that MetS was present in $9.1 \%$ by the ATP III definition and $14.8 \%$ had MetS when the IDF definition was used. ${ }^{59}$ In Saudi Arabia, the prevalence of MetS using the IDF definition was $18 \%$ among 180 obese 9 - to 12 -year-olds. ${ }^{60}$ Also using the IDF definition in Lebanese adolescents, Nasreddine et $\mathrm{al}^{61}$ found that $21.2 \%$ of the 104 obese adolescents (mean age $16 \pm 1.3$ years) had MetS, $3.8 \%$ of the 78 overweight adolescents (mean age $16.4 \pm 1.4$ years) had MetS, and $1.2 \%$ of the 81 healthy weight adolescents (mean age 16.8 years) had MetS. In Iran, according to the ATP III definition, MetS has been found in 3.3\% of Iranian adolescents $(n=450$, age $15-18$ years $) .{ }^{62}$ In a sample of 321 overweight, obese, and extremely obese adolescents from Brazil (obesity defined using the Centers for Disease Control and Prevention 2000 definition, ${ }^{19}$ MetS was found in around $18 \%$ of the 10 - to 16-year-old adolescents using the IDF definition. ${ }^{63}$ Similarly, in the US, ${ }^{64}$ it was found that $>50 \%$ of obese children and adolescents $(n=439$, aged $4-20$ years) had MetS according to definitions modified from ATP III and WHO. ${ }^{24}$ In summary, global studies suggest that, as in the present study, MetS is relatively common among obese adolescents.

The present study had a number of strengths. Our participants were generally a fairly homogenous group of Kuwaiti adolescents living in Kuwait City and recruited from three State schools who were examined for the presence of cardiometabolic risk factors, including MetS. The use of traditional markers for cardiovascular disease (ie, lipid profile and blood pressure), multiple markers for inflammation (ie, CRP, IL-6, and ICAM), and, for the first time, adiponectin in a sample of Kuwaiti adolescents, assessment of insulin resistance as well as liver function, all add to the novelty of our study.

However, our study had a number of limitations. First, it was not possible to conduct Tanner staging, due to social/ cultural and practical reasons. Second, the optimal cutoff to define abnormality for a number of the cardiometabolic risk factors is unclear, but widely used cutoffs were chosen for the present study. Third, no data on changes in cardiometabolic risk factors during obesity treatment were available. Improvements in cardiometabolic risk profile might increase engagement with obesity treatment. Nonetheless, the relatively high prevalence of abnormal values for cardiometabolic risk factors found in the present study could be a useful aid to engage more families into participating in adolescent obesity treatment in future, and might also increase the level of commitment to participation by those who do take part. 


\section{Conclusion}

The present study suggests that a number of cardiometabolic risk factors and MetS are prevalent in obese Kuwaiti adolescents. This observation might provide impetus to future strategies to treat pediatric obesity and to prevent or delay the appearance of cardiovascular disease and diabetes mellitus in the future adult generation. The observation might also be used to encourage greater engagement with treatment among families.

\section{Acknowledgments}

We thank members of the Ethical Committee of the Ministry of Health - Kuwait for the opportunity. We also thank the research assistants, Badreya Al Mirshed and Dalal Al Fadhli, for their valuable work and adherence to the study protocol, and all staff of Al-Sabah laboratory and their head technician, Mrs Haifa'a Al-Mukhaizeem. Funding: Scottish Funding Council and Civil Services Commission - Kuwait.

\section{Disclosure}

The authors report no conflicts of interest in this work.

\section{References}

1. Franks PW, Hanson RL, Knowler WC, Sievers ML, Bennett PH, Looker HC. Childhood obesity, other cardiovascular risk factors, and premature death. N Engl J Med. 2010;362(6):485-493.

2. Lenz A, Diamond FB Jr. Obesity: the hormonal milieu. Curr Opin Endocrinol Diabetes Obes. 2008;15(1):9-20.

3. Freedman DS, Khan LK, Dietz WH, Srinivasan SR, Berenson GS. Relationship of childhood obesity to coronary heart disease risk factors in adulthood: the Bogalusa Heart Study. Pediatrics. 2001;108(3): $712-718$.

4. Kolterman OG, Gray RS, Griffin J, et al. Receptor and postreceptor defects contribute to the insulin resistance in noninsulin-dependent diabetes mellitus. J Clin Invest. Oct 1981;68(4):957-969.

5. Al-Shawi A. The dietary patterns and food habits of Kuwaiti housewives of 3 educational levels. Education Journal of Kuwait University. 1985;2(5):9-13.

6. Beauloye V, Zech F, Tran HT, Clapuyt P, Maes M, Brichard SM. Determinants of early atherosclerosis in obese children and adolescents. J Clin Endocrinol Metab. 2007;92(8):3025-3032.

7. Reilly JJ, Methven E, McDowell ZC, et al. Health consequences of obesity. Arch Dis Child. 2003;88(9):748-752.

8. Juonala M, Magnussen CG, Berenson GS, et al. Childhood adiposity, adult adiposity, and cardiovascular risk factors. $N$ Engl J Med. 2011;365(20):1876-1885.

9. Alwan A. Global status report on noncommunicable diseases 2010. World Health Organization; 2011.

10. Strong JP, Malcom GT, Newman WP 3rd, Oalmann MC. Early lesions of atherosclerosis in childhood and youth: natural history and risk factors. J Am Coll Nutr. 1992;11 Suppl:51S-54S.

11. Zieske AW, Malcom GT, Strong JP. Natural history and risk factors of atherosclerosis in children and youth: the PDAY study. Pediatr Pathol Mol Med. 2002;21(2):213-237.

12. van Emmerik NM, Renders CM, van de Veer M, et al. High cardiovascular risk in severely obese young children and adolescents. Arch Dis Child. 2012;97(9):818-821.
13. 1'Allemand-Jander D. Clinical diagnosis of metabolic and cardiovascular risks in overweight children: early development of chronic diseases in the obese child. Int J Obes. 2010;34 Suppl 2: S32-S36.

14. Schwimmer J, Deutsch R, Kahen T, Lavine J, Stanley C, Behling C. Prevalence of fatty liver in children and adolescents. Pediatrics. 2006;118(4):1388-1393.

15. Strauss RS, Barlow SE, Dietz WH. Prevalence of abnormal serum aminotransferase values in overweight and obese adolescents. J Pediatr. 2000;136(6):727-733.

16. Weiss R, Kaufman FR. Metabolic complications of childhood obesity: identifying and mitigating the risk. Diabetes Care. 2008;31 Suppl 2: S310-S316.

17. Boodai SA, Reilly JJ. Health related quality of life of obese adolescents in Kuwait. BMC Pediatr. 2013;13(1):105.

18. Boodai SA, McColl JH, Reilly JJ. Randomised controlled trial of a good practice approach to treatment of adolescent obesity in Kuwait: National Adolescent Treatment Trial for Obesity in Kuwait (NATTO). Trials. 2014;15:234.

19. Kuczmarski RJ, Ogden CL, Grummer-Strawn LM, et al. CDC growth charts: United States. Adv Data. 2000;314:1-27.

20. Keskin M, Kurtoglu S, Kendirci M, Atabek ME, Yazici C. Homeostasis model assessment is more reliable than the fasting glucose/insulin ratio and quantitative insulin sensitivity check index for assessing insulin resistance among obese children and adolescents. Pediatrics. 2005;115(4):e500-e503.

21. World Health Organization. Definition and diagnosis of diabetes mellitus and intermediate hyperglycaemia: report of a WHO/IDF consultation; 2006.

22. Genuth $\mathrm{S}$, Alberti KG, Bennett $\mathrm{P}$, et al. Follow-up report on the diagnosis of diabetes mellitus. Diabetes Care. 2003;26(11):3160-3167.

23. Ahmed F, Waslien C, Al-Sumaie MA, Prakash P, Allafi A. Trends and risk factors of hyperglycemia and diabetes among Kuwaiti adults: National Nutrition Surveillance Data from 2002 to 2009. BMC Public Health. 2013;13:103.

24. Alberti KG, Zimmet PZ. Definition, diagnosis and classification of diabetes mellitus and its complications. Part 1: diagnosis and classification of diabetes mellitus provisional report of a WHO consultation. Diabet Med. 1998;15(7):539-553.

25. Williams CL, Hayman LL, Daniels SR, et al. Cardiovascular health in childhood: a statement for health professionals from the Committee on Atherosclerosis, Hypertension, and Obesity in the Young (AHOY) of the Council on Cardiovascular Disease in the Young, American Heart Association. Circulation. 2002;106(1):143-160.

26. Sharma S, Lustig RH, Fleming SE. Identifying metabolic syndrome in African American children using fasting HOMA-IR in place of glucose. Prev Chronic Dis. 2011;8(3):A64.

27. Madeira IR, Carvalho CN, Gazolla FM, de Matos HJ, Borges MA, Bordallo MA. [Cut-off point for Homeostatic Model Assessment for Insulin Resistance (HOMA-IR) index established from Receiver Operating Characteristic (ROC) curve in the detection of metabolic syndrome in overweight pre-pubertal children]. Arq Bras Endocrinol Metabol. 2008;52(9):1466-1473. Portuguese.

28. Arshi M, Cardinal J, Hill RJ, Davies PS, Wainwright C. Asthma and insulin resistance in children. Respirology. 2010;15(5):779-784.

29. Jolliffe CJ, Janssen I. Distribution of lipoproteins by age and gender in adolescents. Circulation. 2006;114(10):1056-1062.

30. Panel NE. National Cholesterol Education Program (NCEP): highlights of the report of the Expert Panel on Blood Cholesterol Levels in Children and Adolescents. Pediatrics. 1992;89(3):495-501.

31. Sohn W, Jun DW, Kwak MJ, et al. Upper limit of normal serum alanine and aspartate aminotransferase levels in Korea. J Gastroenterol Hepatol. 2013;28(3):522-529.

32. Siest G, Schiele F, Galteau MM, et al. Aspartate aminotransferase and alanine aminotransferase activities in plasma: statistical distributions, individual variations, and reference values. Clin Chem. 1975;21(8):1077-1087. 
33. Schwimmer JB, McGreal N, Deutsch R, Finegold MJ, Lavine JE. Influence of gender, race, and ethnicity on suspected fatty liver in obese adolescents. Pediatrics. 2005;115(5):e561-e565.

34. Pearson TA, Mensah GA, Alexander RW, et al. Markers of inflammation and cardiovascular disease: application to clinical and public health practice. A statement for healthcare professionals from the Centers for Disease Control and Prevention and the American Heart Association. Circulation. 2003;107(3):499-511.

35. Jaye DL, Waites KB. Clinical applications of C-reactive protein in pediatrics. Pediatr Infect Dis J. 1997;16(8):735-746; quiz 46-47.

36. Macy EM, Hayes TE, Tracy RP. Variability in the measurement of C-reactive protein in healthy subjects: implications for reference intervals and epidemiological applications. Clin Chem. 1997;43(1): $52-58$.

37. Sack U, Burkhardt U, Borte M, Schadlich H, Berg K, Emmrich F. Agedependent levels of select immunological mediators in sera of healthy children. Clin Diagn Lab Immunol. 1998;5(1):28-32.

38. Warnberg J, Moreno LA, Mesana MI, Marcos A. Inflammatory mediators in overweight and obese Spanish adolescents. The AVENA Study. Int J Obes Relat Metab Disord. 2004;28 Supp1 3:S59-S63.

39. Yamamura M, Yamada Y, Momita S, Kamihira S, Tomonaga M. Circulating interleukin-6 levels are elevated in adult T-cell leukaemia/ lymphoma patients and correlate with adverse clinical features and survival. Br J Haematol. 1998;100(1):129-134.

40. Makni E, Moalla W, Benezzeddine-Boussaidi L, Lac G, Tabka Z, Elloumi M. Correlation of resistin with inflammatory and cardiometabolic markers in obese adolescents with and without metabolic syndrome. Obes Facts. 2013;6(4):393-404.

41. Martos R, Valle M, Morales RM, Canete R, Gascon F, Urbano MM. Changes in body mass index are associated with changes in inflammatory and endothelial dysfunction biomarkers in obese prepubertal children after 9 months of body mass index SD score loss. Metabolism. 2009;58(8):1153-1160.

42. Andrys C, Pozler O, Krejsek J, Derner V, Drahosova M, Kopecky O. Serum soluble adhesion molecules (sICAM-1, sVCAM-1 and sEselectin) in healthy school aged children and adults. Acta Medica (Hradec Kralove). 2000;43(3):103-106.

43. Oh DK, Ciaraldi T, Henry RR. Adiponectin in health and disease. Diabetes Obes Metab. 2007;9(3):282-289.

44. Goksen D, Levent E, Kar S, Ozen S, Darcan S. Serum adiponectin and hsCRP levels and non-invasive radiological methods in the early diagnosis of cardiovascular system complications in children and adolescents with type 1 diabetes mellitus. J Clin Res Pediatr Endocrinol. 2013;5(3):174-181.

45. Tascilar ME, Cekmez F, Meral C, et al. Evaluation of adipocytokines in obese children with insulin resistance. Turk J Pediatr. 2011;53(3): 269-273.

46. Alikasifoglu A, Gonc N, Ozon ZA, Sen Y, Kandemir N. The relationship between serum adiponectin, tumor necrosis factor-alpha, leptin levels and insulin sensitivity in childhood and adolescent obesity: adiponectin is a marker of metabolic syndrome. J Clin Res Pediatr Endocrinol. 2009;1(5):233-239.

47. National High Blood Pressure Education Program. The fourth report on the diagnosis, evaluation, and treatment of high blood pressure in children and adolescents. National High Blood Pressure Education Program (NHBPEP) Working Group on Children and Adolescents. Pediatrics. 2004;114(2 Suppl 4):555-576.
48. Zimmet P, Alberti KG, Kaufman F, et al. The metabolic syndrome in children and adolescents: an IDF consensus report. Pediatr Diabetes. 2007;8(5):299-306.

49. Cook S, Weitzman M, Auinger P, Nguyen M, Dietz WH. Prevalence of a metabolic syndrome phenotype in adolescents: findings from the Third National Health and Nutrition Examination Survey, 1988-1994. Arch Pediatr Adolesc Med. 2003;157(8):821-827.

50. Poyrazoglu S, Bas F, Darendeliler F. Metabolic syndrome in young people. Curr Opin Endocrinol Diabetes Obes. 2014;21(1):56-63.

51. Herouvi D, Karanasios E, Karayianni C, Karavanaki K. Cardiovascular disease in childhood: the role of obesity. Eur J Paediatr. 2013;172(6): 721-732.

52. Weiss R, Caprio S. The metabolic consequences of childhood obesity. Best Pract Res Clin Endocrinol Metab. 2005;19(3):405-419.

53. Visser M, Bouter LM, McQuillan GM, Wener MH, Harris TB. Lowgrade systemic inflammation in overweight children. Pediatrics. 2001;107(1):E13.

54. Srinivasan SR, Bao W, Wattigney WA, Berenson GS. Adolescent overweight is associated with adult overweight and related multiple cardiovascular risk factors: the Bogalusa Heart Study. Metabolism. 1996;45(2):235-240.

55. Kelishadi R, Motlagh ME, Roomizadeh P, et al. First report on path analysis for cardiometabolic components in a nationally representative sample of pediatric population in the Middle East and North Africa (MENA): the CASPIAN-III Study. Ann Nutr Metab. 2013;62(3): 257-265.

56. Kardas F, Kendirci M, Kurtoglu S. Cardiometabolic risk factors related to vitamin $\mathrm{d}$ and adiponectin in obese children and adolescents. Int $J$ Endocrinol. 2013;2013:503270.

57. Makkes S, Renders CM, Bosmans JE, van der Baan-Slootweg OH, Seidell JC. Cardiometabolic risk factors and quality of life in severely obese children and adolescents in The Netherlands. BMC Pediatr. 2013;13:62.

58. Expert Panel on Detection, Evaluation, and Treatment of High Blood Cholesterol in Adults. Executive summary of the Third Report of The National Cholesterol Education Program (NCEP) Expert Panel on Detection, Evaluation, and Treatment of High Blood Cholesterol in Adults (Adult Treatment Panel III). JAMA. 2001;285(19):2486-2497.

59. Al-Isa A, Akanji AO, Thalib L. Prevalence of the metabolic syndrome among female Kuwaiti adolescents using two different criteria. $\mathrm{Br} J$ Nutr. 2010;103(1):77-81.

60. Abdel-Megeid F, Alfawaz H. Metabolic syndrome and risk factors of cardiovascular diseases in obese children. World Applied Science Journal. 2012;20(7):988-996.

61. Nasreddine L, Naja F, Tabet M, et al. Obesity is associated with insulin resistance and components of the metabolic syndrome in Lebanese adolescents. Ann Hum Biol. 2012;39(2):122-128.

62. Mehrkash M, Kelishadi R, Mohammadian S, et al. Obesity and metabolic syndrome among a representative sample of Iranian adolescents. Southeast Asian J Trop Med Public Health. 2012;43(3):756-763.

63. Rizzo AC, Goldberg TB, Silva CC, Kurokawa CS, Nunes HR, Corrente JE. Metabolic syndrome risk factors in overweight, obese, and extremely obese Brazilian adolescents. Nutr J. 2013;12:19.

64. Weiss R, Dziura J, Burgert TS, et al. Obesity and the metabolic syndrome in children and adolescents. N Engl J Med. 2004;350(23): 2362-2374.

Diabetes, Metabolic Syndrome and Obesity: Targets and Therapy

\section{Publish your work in this journal}

Diabetes, Metabolic Syndrome and Obesity: Targets and Therapy is an international, peer-reviewed open-access journal committed to the rapid publication of the latest laboratory and clinical findings in the fields of diabetes, metabolic syndrome and obesity research. Original research, review, case reports, hypothesis formation, expert
Dovepress

opinion and commentaries are all considered for publication. The manuscript management system is completely online and includes a very quick and fair peer-review system, which is all easy to use. Visit http://www.dovepress.com/testimonials.php to read real quotes from published authors. 